\title{
Social recovery during the year following severe head injury
}

\author{
M ICHAEL ODDY A N D ICH A EL H UMPHREY \\ From St Francis Hospital, Haywards Heath, Sussex and St George's Hospital Medical School, London
}

SUMMARY A group of 54 patients who had suffered severe closed head injury (PTA $>24$ hours) were followed from the time of their injury for a period of two years. Relatives were interviewed within the first four weeks to assess the patient's previous personality and social adjustment. Patients and relatives were then assessed personally six and 12 months later and by postal questionnaires after two years. Only six patients were still not back at work after two years but more had not resumed all their leisure activities. Family relationships appeared to have settled down again by this stage but social contacts were still less frequent. Personality changes were associated with prior family relationships, cognitive changes with diminished social contacts whilst premorbid personality and physical deficits were associated with time taken to return to work.

A previous report ${ }^{1}$ describes the level of social recovery achieved by a representative series of 50 young adults six months after a severe closed head injury (PTA $>24$ hours). This paper reports further findings from this prospective study concerning social recovery one year and two years after injury.

\section{Patients and methods}

The sample, collected from a number of hospitals and hospital departments, originally consisted of 54 consecutive patients aged between 16 and 39 years, all of whom had suffered a closed head injury leading to a PTA of more than 24 hours. A close relative was interviewed during the first four weeks following injury in order to assess pre-morbid personality and social adjustment. Using the same assessment procedures the relative was interviewed six and 12 months after injury to assess the current status of the patients. The assessment included a semi-structured interview with a close relative to assess the patient's social adjustment during the two months prior to the assessment and the relative was asked to complete the Katz Adjustment Scales ${ }^{2}$ and a symptom check list. The latter contained 37 items relating to personality

Address for reprint requests: Dr M Oddy, St Francis Hospital, Colwell Road, Haywards Heath, West Sussex, RH16 4EZ.

Accepted 15 May 1980 changes and somatic, sensory, cognitive and psychiatric symptoms. Patients were subjected to a battery of cognitive tests and also asked to complete the symptom check list. Unfortunately, only a postal follow-up was possible two years after injury. Patients and relatives were both sent the symptom check list and a brief questionnaire with items relating to social adjustment, motor and sensory sequelae and personality and cognitive deficits. Some information was received concerning 43 patients at the latest follow up and full information from both relatives and patients was obtained in 35 of these cases (table 1).

A control group of 35 patients who had suffered traumatic limb fractures without injury to the head were also followed up. The two groups were matched for age and socio-economic status. The procedures were identical to those for the head injured patients except that only a brief assessment was carried out at 12 months and no

Table 1 Number of patients and relatives completing each assessment

\begin{tabular}{llllll}
\hline & & Initial & 6 months & 12 months & 2 years \\
\hline $\begin{array}{llllll}\text { Head } \\
\text { injured }\end{array}$ & Patients & 54 & 49 & 44 & 39 \\
& Relatives & 54 & 49 & 43 & 39 \\
Controls & Patients & 35 & 30 & 26 & 19 \\
& Relatives & 35 & 29 & $\begin{array}{l}\text { Not } \\
\text { contacted }\end{array}$ & 17 \\
\hline
\end{tabular}


relatives were contacted at this stage. Thirty control patients were reassessed at six months and 19 returned the questionnaire after two years.

\section{Results}

Physical status Patients in this series had PTAs ranging from the minimum 24 hours to 130 days. The mean was 19.81 days with a standard deviation of 25.85 days. The median PTA was seven days.

Six months after injury 29 patients were completely free of any motor or sensory impairment. Six had minor residual symptoms from orthopaedic injuries and a further six had more disabling residual orthopaedic problems. Four were still suffering from minor neurological motor dysfunction and two were still suffering more severe neurological motor dysfunction. Three patients suffered from an arm amputation, partial blindness and paraplegia respectively. An Activities of Daily Living assessment at six months revealed only four patients who were not fully independent for these activities. Two of these resulted from orthopaedic injuries, one from paraplegia and one from hemiplegia. All four showed some improvement between six and 12 months but none became completely independent.

Work Forty-five of the head injured patients seen at six months had been in full-time jobs at the time of their accident. Of these, 30 had returned to work within six months. A further seven returned during the next six months but only one patient returned to work between one and two years after injury (table 2 ).

We were unable to contact a further patient who had been unemployed at the one year followup but of the remaining six, it was judged that there was still a likelihood of two or three, at least, returning to work.

Table 2 Numbers of patients returning to work at various stages after injury

\begin{tabular}{|c|c|c|c|c|c|c|}
\hline & & $\begin{array}{l}3 \\
\text { months }\end{array}$ & $\begin{array}{l}6 \\
\text { months }\end{array}$ & $\begin{array}{l}12 \\
\text { months }\end{array}$ & $\begin{array}{l}24 \\
\text { months }\end{array}$ & $\begin{array}{l}\text { Known to } \\
\text { be not } \\
\text { back } \\
\text { at } 24 \\
\text { months }\end{array}$ \\
\hline \multirow[t]{2}{*}{$\begin{array}{l}\text { Head } \\
\text { injured }\end{array}$} & $\begin{array}{l}\text { Severe } \\
\text { (PTA 1-7 } \\
\text { days) }\end{array}$ & 10 & 18 & 20 & 20 & 1 \\
\hline & $\begin{array}{l}\text { Very severe } \\
\text { (PTA > } 7 \text { days }\end{array}$ & $s^{4}$ & 12 & 17 & 18 & 5 \\
\hline \multicolumn{2}{|c|}{ Controls } & 7 & 23 & 28 & 29 & 0 \\
\hline
\end{tabular}

NB It is assumed that those back at work at early stages but lost to late follow ups remained at work.
The eight patients who were away from work for more than a year included only one patient with a PTA of less than seven days and only one from socio-economic classes one and two.

None of those back at work had actually been downgraded or had had to take on a less demanding job. However, it did appear that within the job their capabilities may have altered. At the oneyear interview we found evidence of subtle alterations in the expectations of employers. For example, a policeman and a marine engineer had been confined to office duties, skilled workers were no longer required to work at heights and were working under closer supervision.

At the two-year follow-up, nine patients rated their ability to work as poorer than before the accident. Compared to those who rated their working ability as not having been affected, these patients also complained of significantly more subjective symptoms, and had obtained lower scores on certain memory tests when these were administered at six months.

Our data suggest that speed of return to work is influenced more by physical disability than by personality or cognitive deficits in this group of moderately severely injured patients. Pre-morbid personality traits did, however, show a relationship to speed of return to work. Premorbid nervousness and suspiciousness tended to delay return to work, whilst verbal expansiveness (a tendency to be brash) tended to lead to a more rapid return.

Leisure activities At 12 months $50 \%$ of patients were still engaged in fewer leisure activities than prior to their accidents, and after two years this situation was unchanged.

Those who had fewer leisure activities had longer PTAs than those who had resumed their activities $(p<0 \cdot 02)$. However, although ability to resume leisure activities appeared to be related in a general way to severity of injury, it was difficult to determine which aspects of recovery were implicated. Unlike return to work, failure to resume leisure activities did not appear to be the result of physical disability. Table 3 shows that only just over half of those impaired had suffered any physical disability as a result of their accident, and of these many were only mild physical injuries from which the patient had apparently made a full recovery. In fact, it appeared that the impairment of leisure activities reflected a tendency to participate in leisure activities less frequently rather than to give them up completly.

Those patients who complained of finding "difficulty in becoming interested in anything" on the symptom check list clearly had fewer leisure ac- 
Table 3 Physical injury and impairment of leisure activities at 12 months

\begin{tabular}{llll}
\hline & & Present & Absent \\
\hline Physically & Yes & 9 & 9 \\
injured & No & 7 & 18 \\
\hline
\end{tabular}

$x^{2}=1 \cdot 33$, NS.

tivities (table 4). However, the fact that many patients with fewer leisure activities did not report this difficulty suggests that factors other than motivational ones prevented a resumption of leisure activities, or that some patients lacked insight into their motivational problems.

Further evidence for a motivational deficit is the fact that contrary to normal expectations, those with fewer leisure activities than prior to the injury, were not reported to show more boredom (defined as subjective distress due to inactivity). Nor was boredom related to return to work or to the number of social contacts. Thus it appeared that a number of our patients, though physically capable of participating in leisure activities, were content to lead a more restricted life than hitherto during the two years following head injury.

Social contact On a composite measure of social contact it was found that those patients with a PTA exceeding seven days tended to have fewer social encounters at both six months and 12 months. Further analysis revealed that at six months this reflected less contact with close friends and a less frequent exchange of visits with friends. At 12 months, however, although this group of very severely injured patients no longer paid significantly fewer social visits than prior to their injury they still received significantly fewer. By this stage they had a similar number of close friends compared to before the accident.

At the two-year follow-up the very severely injured group (PTA $>7$ days) tended to report having fewer friends than the control group, but this did not reach significance. However, a tendency for the head injured group as a whole to report fewer social outings did reach significance

Table 4 Impairment of leisure activities and subjective complaint of apathy

\begin{tabular}{llll}
\hline & & \multicolumn{2}{l}{ Leisure activities } \\
\cline { 3 - 4 } & & Same & Fewer \\
\hline $\begin{array}{llll}\text { Difficulty in becoming } \\
\text { interested in anything }\end{array}$ & No & 28 & 10 \\
\cline { 3 - 4 } & Yes & 3 & 7 \\
\hline
\end{tabular}

Fisher exact prob $=0.013$. $(p<0.005)$, and once again those with a PTA of more than seven days were clearly the most disadvantaged.

The influence of physical disability upon social contact was investigated by comparing those patients who had suffered a sensory or motor deficit with those who had not. No difference between these groups was found on the composite measure of social contact.

Those patients said by their relatives to have suffered an adverse personality change were compared with those who had not but again no significant difference was found on the composite social contact measure.

Limited social contact was related to poor performance on certain cognitive tests (Inglis Paired Associate Learning test and Wechsler Logical Memory; $\mathrm{p}<0.05$ in both cases).

Family relationships These findings relate to single patients living with their family of origin. The tendency for the very severe sub-group to be more dependent on their parents at six months was no longer significant at 12 months. However, there were indications of deteriorating relationships between this group of patients and their siblings at 12 months. A trend towards increased friction fell just short of statistical significance, but there was some evidence of diminished communication between patients and siblings $(p<0 \cdot 05)$. No such deterioration was reported concerning the relationships of parents and patients.

At two years, both patients and relatives were asked to rate how well they got on with the nuclear family as a whole. Neither reported poorer relationships than the control group.

At the 12-month follow-up, those patients reported to have suffered adverse personality changes had significantly poorer family relationships than those without personality changes, but only when the patient had at least one sibling living at home $(\mathrm{p}<0.05)$.

Poor family relationships were also associated with a high number of subjective complaints. The correlation between the composite measure of family relationships and the patient's own report of subjective symptoms was low $(\mathrm{rho}=+0.31)$ but significant $(p<0.05)$. However, when correlated with the relatives' view of the number of subsubjective symptoms suffered by the patient, the coefficient was higher ( $\mathrm{rho}=+0.67, \mathrm{p}<0.001$ ).

Marital relationships Only 12 married patients were followed up. At 12 months the only rating which showed any sign of a change was the rating of affection felt by the spouse towards the patient. Of the seven patients in the very 
severe group, three spouses were rated as feeling less affectionate towards their partner. No significant change was found in sexual behaviour and in only one case was any problem mentioned. In this case, the patient suffered from partial impotence and the wife reported that she felt that both partners received less satisfaction from sex even when technically satisfactory.

At the two-year stage only one spouse and two patients reported their marital relationships to be less satisfactory than prior to the accident.

One couple had divorced between the six and 12-month assessments, but their marriage had been rated as on the point of breakdown at the time of the injury and it is unlikely that the accident influenced the outcome.

\section{Discussion}

The study has plotted the course of recovery for a group of young adult patients during the year following severe closed head injury and, less rigorously during the second year. The primary emphasis has been on the patients' social reintegration. Previous studies have often used return to work as a measure of outcome after recovery from head injury. The results of this study suggest that it is not a sensitive index. Most of the patients in this series were able to return to work, but a number were restricted in their activities and believed that they had still not regained their full working capacity two years after injury.

Certain other aspects of daily life appeared to suffer even more. The more severely injured (PTA $>7$ days) had still not resumed all their leisure activities at the two-year follow-up. Similarly they still had a more restricted social life two years after injury. Family relationships, despite signs of disruption after 12 months, appeared to have settled again by the two-year assessment.

The results repeatedly revealed that those with a PTA of more than a week were slower to recover than those with shorter PTAs. This was true in each area of social life considered. Indeed by 12 months the recoveries of the less severely injured appeared more or less complete. The very severely injured patients were the only ones for whom social contact and family relationships were significantly disturbed at any stage.

Apart from length of PTA, the variables related to return to work were physical injury and various measures of premorbid personality. Other aspects of post-traumatic status such as cognitive and personality changes did not appear to be important.
This finding conflicts with those of previous studies (for example, Fahy et $a l^{3}$, Bond, ${ }^{4}$ ) and probably reflects the comparatively mild nature of cognitive and personality changes in the present sample. In the group as a whole cognitive changes were no longer significant by 12 months, and many relatives prevaricated about whether or not the patient had suffered a personality change.

It is interesting that at 12 months only eight patients had failed to return to work, whereas 16 had not resumed all their leisure activities. It is unlikely that purely physical difficulties would differentially affect the resumption of work and leisure activities. Although it is possible that the rating of leisure activities was simply more sensitive to disruption than the measure of work capacity, this finding does suggest motivational difficulties. The reasons for loss of social contact were not altogether clear. It was not simply a case of physical restrictions. At both six and 12 months the number of visits received by the very severely head injured patients showed a greater degree of change than the number of visits made. In contrast, the control patients made fewer visits (trend significant at $10 \%$ level) but tended to receive more. The possibility that personality changes were associated with this loss of contact was not borne out by the statistical analysis. Unlike other aspects of social recovery, the extent of social contacts was related to defective performance on memory tests. Possibly these deficits rendered the patient socially inept.

Personality changes did appear to influence relationships with the family. The main locus of friction was reported to be between patient and siblings. This may simply reflect a greater willingness on the part of parents to admit that this form of friction occurs whilst denying that they personally are involved. Nevertheless, sibling relationships may be more vulnerable and likely to disintegrate under this form of stress.

This study has also found clear evidence to support the widespread contention that premorbid personality affects social recovery. Interestingly, it appeared that certain personality characteristics were associated with failure to resume activities whilst others were associated with problems in personal relationships. Pre-accident "nervousness" appeared to hinder resumption of both work and leisure activities, whilst a tendency towards being "verbally expansive" appeared to promote it. The nervous individual may be slower to regain active roles in life which the brash person rapidly resumes. Patients with high premorbid ratings on a factor labelled "helplessness" tended to have poor 
family relationships and few social contacts after head injury.

Rehabilitation of the head injured patient tends to be directed towards restoring physical capacity with the ultimate goal of return to work. In our sample physical factors were important for the resumption of work but not for other aspects of social recovery. A wider approach to rehabilitation is needed. Thomsen's $s^{5}$ patients complained more about their loneliness than any other aspect of their situation. Miller and Ingham ${ }^{6}$ have shown that lack of a close friend is associated with anxiety and depression, and Hyman ${ }^{7}$ found that social isolation amongst stroke patients was correlated with poor motivation for rehabilitation. A number of studies have demonstrated the importance of good family relationships for successful rehabilitation. It seems probable that motivation for all aspects of rehabilitation could be improved if more attention were directed towards problems of social isolation and family relationships.

This study was in part financed by Action Research for the Crippled Child. We thank Mr John
Preston for his helpful comments on an earlier draft of this paper.

\section{References}

1 Oddy MJ, Humphrey ME, Uttley D. Subjective impairment and social recovery after closed head injury. J Neurol Neurosurg Psychiatry 1978; 41: 611-6.

2 Katz MM, Lyerly SB. Methods for measuring adjustment and social behaviour in the community. Psychol Reports 1963; 13:503-35.

3 Fahy TJ, Irving $\mathbf{M H}$, and Millac P. Severe head injuries a six year follow-up. Lancet 1967; 2:475-9.

4 Bond MR. Assessment of the psychosocial outcome after severe head injury. In: Outcome of Severe Damage to the C.N.S. Ciba Foundation Symposium (34) 1975:141-53.

5 Thomsen IV. The patient with severe head injury and his family - a follow-up study of 50 patients. Scand J Rehab Med 1974; 6:180-3.

6 Miller P McC, Ingham JG. Friends, confidants and symptoms. Social Psychiat 1976; 11:51-8.

7 Hyman MD. Social psychological determinants of patients' performance in stroke rehabilitation. Arch Phys Med Rehab 1972; 53:217-26. 